\title{
An Investigation on Well-being and Emotional Intelligence among Young Adults
}

\author{
Dr. Sanjeev Kumari \& Dr. Sandeep Panchal \\ ${ }^{1}$ Dr. Sandeep Panchal, Assistant Professor, Dept. of Psychology, Rajiv Gandhi University(A \\ Central University), Doimukh, Itanagar, Arunachal Pradesh, India, \\ ORCID: https://orcid.org/0000-0002-5249-5397 \\ Email: sandeep.panchal@ rgu.ac.in
}

\begin{abstract}
Subjective well-being is a psychological aspect of life satisfaction. An individual's psychological well-being affects how a person thinks and feels. There are numerous factors which can influence the subjective well-being of an individual. One of the most important factors is emotional intelligence. Emotional intelligence has been preoccupying a significant place in well-being literature. Goleman (1998) defines it as "emotional awareness and emotional management abilities give the ability to balance emotion and reason in order to maximise long-term enjoyment". It entails recognising one's own and others feelings, managing one's own emotions, and adapting to others emotions. The objective of this study was to examine the nature of the relationship between emotional intelligence and psychological well-being among young adults who are following bachelor degrees from recognized national universities. The sample consists of 200 participants both male and female of age range 19 to 23 years mean age is 21, included in this study. Well-being Inventory and Multidimensional Measures of Emotional Intelligence were administered to measure the subjective well-being and emotional intelligence. Results showed that selfawareness, managing emotions, motivating oneself, handling relations dimension of emotional intelligence evidenced strong positive associations with well-being positive affect, well-being negative affect and well-being total dimensions of well-being. Stepwise regression analysis disclosed two predictors of well-being i.e. managing emotions and motivating oneself. These results have important implications with regard to our current understanding of the relationships between well-being and emotional intelligence.
\end{abstract}

Keywords: Emotional Intelligence, Well-being.

\section{Introduction}

Young adulthood is a critical period for human development. There are various pressures and challenges for young people. They need to deal with considerable change in their lives at this time: growing academic expectations, changing social relationship with family and peers and emotional changes associated with maturation. Nowadays, the transition to adulthood is more continuous and variable than in the past. Early adulthood experiences differ substantially by gender, race and ethnicity, and socioeconomic class, and young individuals take longer to reach economic and psychological autonomy. The term "well-being" relates to how people 
feel about the quality of their lives, and it involves both emotional and cognitive responses. Well-being is a somewhat malleable concept that refers to how individuals feel about their daily lives. The most of previous studies have defined well-being as one's subjective happiness with one's life (Diener et al., 1999; Pavot \& Diener, 2003; Van Praag, Frijters, \& Ferrer-i-Carbonell, 2003). Salami (2010) defined psychological well-being as a state that develops from delight with one's physical health, one's self as a person, and one's close interpersonal relationship. The term "well-being," which refers to an optimal psychological condition is the best construct that can be described from two different angles. Well-being is defined by the hedonic perspective as a favourable judgement of one's own life, and it has been connected to feelings of contentment and emotional stability, as well as subjective wellbeing. Eudemonic well-being, which corresponds to psychological well-being, emphasizes personal development, self-fulfilment, exploring one's own potential and planning for the future, and contributing to the well-being of others (Deci \& Ryan, 2008; Ryff \& Singer, 2008; Waterman et al., 2010; Adler \& Seligman, 2016).

A person is said to have high subjective well-being if he or she mostly experiences life satisfaction and joy rarely experiences unpleasant emotions such as sadness and anger. On the other hand if a person dissatisfied with life, experience lesser joy and affection and often experiences negative emotions such as anger or anxiety is tend to possess low subjective well-being.For describing psychological well-being, different researchers employed different concepts and terminology, such as self-concept and self-esteem (Rosenberg, 1965); mood, affect, quality of life, mentality, and subjective well-being (Diener et al., 1985). The major components of psychological well-being or mental health are self-esteem, self-actualization, stress, anxiety, and depression. Good mental health is important for managing with life's problems.

Emotional intelligence is one of the major determinants of the quality of people's interpersonal relationships. Emotional intelligence refers to the ability to observe and discriminate between one's own and others' feelings and emotions, as well as to use this information to guide one's thinking and actions (Mayer \& Salovey, 1990). This type of intelligence will play a role in maintaining a healthy psychological state.

Emotional intelligence represents the ability to effectively process, use, understand, and manage emotional information (Matthews, Zeidner, \& Roberts, 2004; Mayer, Salovey, \& Caruso, 2000). The primary theoretical model of emotional intelligence proposes four different branches of abilities, structured in a hierarchy from the simplest branch (the ability to perceive emotions) to the most complex branch (the ability to manage emotions, such that positive emotional responses to events are enhanced and negative responses to events are diminished) (Mayer et al., 2008). Individuals with these abilities may be better able to cope with the daily stresses, establish more meaningful intimate relationships, and be more socially competent in general (Zeidner, Matthews, \& Roberts, 2009). As a result, those with high emotional intelligence may be more likely to have higher levels of well-being, or "optimal psychological functioning and experience" (Ryan \& Deci, 2001) 


\section{Well-being and Emotional Intelligence}

Positive emotional intelligence is correlated with greater psychological adjustment and selfesteem, whereas low or negative emotional intelligence is associated to depression, harmful, and troubling conduct (Petrides \& Furnham, 2000). Many studies have shown a correlation between emotional intelligence and people's mental health. In young school-aged children, higher levels of emotional intelligence correspond to higher levels of happiness, while lower levels of emotional intelligence lead to psychopathology (Emotional Intelligence, 1998). The relationship between emotional intelligence and psychological well-being has been well established through empirical studies (Mavroveli, et al., 2007; \& Mikolajczak et al., 2008) as indicated earlier. Emotional intelligence was found to be a strong predictor of a variety of life outcomes, including mental and physical health, in meta-analytic investigations. Because of their power to recover after a negative mood induction, people who have a better perception, understanding, and management of emotions have a lower risk of acquiring maladaptive emotional states including mood and anxiety disorders (Schutte et al., 2007).Higher emotional intelligence has therefore been associated with healthy psychological functioning that includes higher optimism, greater feelings of emotional well-being and low levels of depression (Mikolajczak, Petrides, Coumans \& Luminet, 2009; Salovey Mayer, Goldman, ITurey \& Palfaiet, 1995; \& Schutte et al., 2002). In the relationship between emotional intelligence and health, which includes mental health, physical health and psychosomatic health, it was found that people with a high emotional intelligence will be experience less mental health issues (Petrides, Perez-Gonzalez \& Furnham, 2007; Schutte et al., 2007). Consequently, it has been theorised that individuals who are able to regulate and understand their emotions have better experience of emotional health (Kafetsios \& Zampetakis, 2008; Lyubomirsky, King \& Diener, 2005; Mikolajczak et al., 2009). Brackett and Mayer (2003) also assessed the positive association between the emotional intelligence, and Ryffes psychological well-being scale. Palmer et al., (2002) found a significant relationship between emotional intelligence and life satisfaction among Spanish undergraduates, which supports these findings. In addition, Augusto et al., (2008), Extremera \& Fernandez- Berrocal (2006), and Gohm and Clore (2002) found positive associations between emotional intelligence and psychological well-being in their research. There is a strong association between emotional intelligence and psychological well-being, according to several theoretical and empirical investigations. It suggests that those with a greater level of emotional intelligence have a better psychological well-being. The main aim of this study is to investigate the association between emotional intelligence and psychological well-being.The association between emotional intelligence and psychological well-being has been explored empirically and conceptually. When compared to people with lower emotional intelligence, it shows that highly emotional intelligent people are more likely to experience higher psychological wellbeing (Mavroveli, Petrides, Rieffe, \& Baker, 2007; Schutte, Malouff, Thorsteinsson, Bhullar, \& Rooke, 2007; Gallagher \& Vella-Brodrick, 2008; Mikolajczak, Nelis, Hansenne, \& Quoidbach, 2008; Zeidner, Matthews, \& Roberts, 2009).

On the other hand the role of gender has been discovered to play an influence in both emotional intelligence and psychological well-being which is both influential and 
contradictory. Both emotional intelligence and psychological well-being are influenced differently by gender (Castro-Schilo \& Kee, 2010; McIntryre, 2010; Schutte, Malouf, Simunek, McKenly \& Holland, 2002; Thomsen, Mehlesen, Viidik, Sommerlund \& Zachariae, 2005). Similarly, a significant difference in emotional intelligence and psychological wellbeing between urban and rural adolescents. In terms of emotional intelligence and psychological well-being of adolescents, it was observed that there is a strong interaction relationship between gender and place of residence. Emotional intelligence is strong predictor of better psychological adjustment and high self-esteem, whereas low or negative emotional intelligence is significantly related to depression, damaging and disturbing behaviour (Petrides \& Furnham, 2000). Mehmood and Gulzar (2014) investigated the relationship between emotional intelligence and adolescent psychological well-being (depression and self-esteem), found a significant positive relationship between emotional intelligence and self-esteem and a negative relationship between emotional intelligence and depression, suggesting that emotionally intelligent people adopt flexible patterns of life, enables them to adopt attitudinal changes that protect them from distress. Emotional intelligence and life success are connected in a progressive structural chain.High emotional intelligence encourages or motivates a person to develop a positive sense of self, which helps in the development of high self-esteem. People with high self-esteem are more open and assertive, and they deal with challenges more effectively and sensibly, resulting in excellent performance and a happy life.

\section{Objective of the study}

Main objective of the study are:

- To examine the relationship between emotional intelligence and well-being

- To explore whether emotional intelligence dimensions significantly predict well-being among young adults.

\section{Conceptual Framework}

The study adopted the following conceptual framework based on the literature review:

Table 1: An abstract framework illustrating the connection between well-being and Emotional Intelligence.

\begin{tabular}{|l|l|}
\hline Independent variable & Dependent variable \\
\hline Emotional intelligence & Well-being \\
Self-awareness & Well-being positive affect \\
Managing emotion & Well-being negative affect \\
Motivating oneself & Well-being total \\
Empathy & \\
Handling relations & \\
& \\
\hline
\end{tabular}




\section{Hypotheses}

H1: Emotional Intelligence dimensions will significantly correlate with psychological wellbeing of young adults.

H2: Well-being is expected to correlate positively with self-awareness, motivating oneself, managing emotions, handling relation.

H3: Well-being is expected to correlate negatively with empathy.

H4: The dimension of emotional intelligence would significantly predict well-being among young adults.

\section{Method}

\section{Participants}

The present study was conducted on a sample of 200 undergraduates of Haryana, India. The age range of the sample was from 19 to 23 years with the mean age of 21 years. The sample was selected from students of under graduate courses who were given their informed consent and willing to participate in the study.

\section{Demographic Data Sheet}

For the purpose of study we used self-developed demographic data sheet for obtaining demographic information of participants. Demographic data sheet included age, gender, socioeconomic status, marital status, academic grades, parent's education and occupations and disability status of participants.

\section{Tools for the study}

Subjective Well-Being Inventory (Sell \& Nagpal 1992): Subjective Well-Being Inventory measures feelings of well-being experienced by an individual in day-to-day life concerns. It consists of 40 items, measuring 11 factorial dimensions: general wellbeing positive and negative effect, expectation-achievement congruence, confidence in coping, transcendence, family group support, social support, primary group unconcern, Inadequate mental mastery, a sense of ill health, and a lack of social interaction. Higher scores indicate more subjective well-being. The total sum of the 40 items gives the total subjective well-being score. The total score on negative items can provide score on well-being negative affect and total score on positive items can provide score on well-being positive affect. The inventory is scored by attributing the values 3,2 and 1 to response categories of positive items and 1,2 and 3 to the negative items. Thus the range of scores is 40 (minimum) to 120 (maximum). This scale has high inter-rater reliability, inter-scores reliability, and test-retest reliability. The scale showed a high level of significance and validity. The reported test retest reliability of the inventory is 0.79 and the validity is 0.86 .

Multidimensional Measure of Emotional Intelligence (Dorolia, 2003): It is measured the emotional intelligence which was developed by Dorolia (2003) to provide reliable and valid measurement of emotional intelligence (EI) in accordance with Goleman's (1995) model. Goleman $(1995,1996)$ claimed emotional intelligence to be the best predictor of success in life. According to Goleman's model, MMEI is comprised of 80 multiple - choice item distributed in five dimensions, self-awareness (SA), Managing Emotion (ME), Motivating 
Oneself (MO), Empathy (E), Handling Emotion (HR), each consisting 16 items. Each item is answered on a Five-Point Scale i.e., very true, mostly true, somewhat true, mostly false, and very false. The scoring pattern is-positive item scoring very true 5 , mostly true 4 , somewhat true 3, mostly false 2 and very false 1 , for negative items scoring follow opposite patternvery true 1 , mostly true 2 , somewhat true 3 , mostly false 4 , very false 5 .

\section{Procedure}

The questionnaires were distributed each classroom group as part of the data collection procedure. First and foremost, educational centres were contacted to explain the study's objectives and obtain permission to complete the questionnaires. In the same way, anonymity in the answers, the confidentiality of the obtained data, and its exclusive use for research purposes was assured. The administration of the questionnaires was carried out during college hours. Participants were also informed about their role in the data collection. On a sample of 200 undergraduates, Subjective Well-Being Inventory and Multidimensional Measure of Emotional Intelligence were administered. These selected tools were administered after giving general instructions. It was ensured that the subjects marked answers for each question. Scoring was done using the manuals.

Statistical Analysis: The obtained data was analysed using SPSS software using Pearson's Product Moment correlation and stepwise Regression.

\section{Results and Discussion}

The present study was conducted to find out the relationship between five dimensions of emotional intelligence and subjective well-being by taking into account five dimensions of emotional intelligence and three dimensions of well-being. A perusal of the inter-correlation matrix shows that there are significant relationships between emotional intelligence dimensions and subjective well-being.

Table 1 Correlation matrix for Emotional Intelligence and Subjective Well-being

\begin{tabular}{|c|c|c|c|c|c|}
\hline VariablesSA & $\overline{M E}$ & $\overline{\mathbf{M}}$ & & EMP & HR \\
\hline WPA & $.17 *$ & $.20 * *$ & $.27 * *$ & -.02 & $.22 * *$ \\
\hline WNA & $.16^{*}$ & $.28 * *$ & $.18 * *$ & $\quad-.09$ & .13 \\
\hline WBT. & $21 * *$ & $.31 * *$ & $.28 * *$ & -.08 & $.21 * *$ \\
\hline
\end{tabular}

The result reveal that well-being positive affect dimension of subjective well-being has correlated positively with self-awareness (.17), managing emotion (.20), motivating oneself (.27), and handling relation (.22) dimensions of emotional intelligence. It suggests that undergraduates reflecting feeling of well-being that are arising out of an overall perception of life functioning smoothly and joyfully also possess Emotional Intelligence. Such individuals recognize a feeling as it is happening handle feeling appropriately by handling fears anxieties 
and sadness. Such individuals always channelize their emotions towards the attainment of goals and also possess the ability of handling social relationships with the help of social competence. The correlation between emotional intelligence and positive affect was highly, practically and positively significant (Field, 2005).

well-being negative affect dimension of well-being has correlated positively with selfawareness (.16), managing emotion (.28), motivating oneself (.18) dimensions of emotional intelligence. All the correlations are significant at .01 levels. The result suggests that individuals reflecting a general depress outlook on life still enjoy emotional intelligence. Such individuals are aware about themselves, can see through a feeling or an emotion, and also try to find ways to handle fears and sadness. Such individuals have emotional intelligence self-control and impulse control and they can manage their emotions socially by exerting social skills.

well-being total dimension of subjective well-being is indicative of positive correlations with self-awareness (.21), managing emotion (.31), similar results were reported by schutte et al.,(1998) that people with a high management of emotions are able to regulate their mood in a more positive direction which is of psychological benefit especially in times of stress. Burrus et al., (2012) indicated that emotional management was strongly related to eudaimonic well-being and the ability to manage emotions was related to hedonic well-being and suggesting a relationship between emotional intelligence and well-being, motivating oneself (.28) and handling relation (.21) dimensions of emotional intelligence. All the correlations are significant at both the level of significance. It suggests that individuals who are enjoying perfect well-being are emotionally competent. Such individuals are observant and good in managing emotion by exerting self-awareness and by realizing the cause behind a feeling. Such individuals have good control over their impulsive and can managing emotion in social situations with the social position competence and social skills. All the correlations are significant at .01 levels. The current findings, which are corroborated by previous studies; indicate that there is a considerable correlation between emotional intelligence and student's well-being (Kaur, 2015; Mehmood \& Gulzar, 2014). Individuals are required to have highly developed social and emotional skills in order to ensure not just their own but also the well-being of others in a radically changing society. peoples who have high level of positive affect in social situations are also likely to experience high level in non-social situations (Oishi, Diener, Suh \& Lucas, 1999). This provides further support for the notion that positive affect accounts for the differences in psychological well-being. People who are able to adequately manage their emotions have a strong social support system (Ciarrochi et al., 2000). Diener and Suh (2001) discovered that emotional intelligence and Ryff's psychological well-being measure have a significant correlation. Carmeli, Yitzhak-Halevy, and Weisberg (2009), investigated that emotional intelligence and psychological well-being components have a positive correlation (self-esteem, life satisfaction, and selfacceptance).Emotional intelligence is a key characteristic of psychological wellbeing, according to Abraham, Meyrav, and Jacob (2009). People with high emotional intelligence had good mental health, which lead to a happy life. They have the potential to be good learners, thinkers, and creators. Gujral, Gupta, and Aneja (2012) found a significant 
correlation between emotional intelligence and total well-being, which both influenced employee behaviour, which is important for job success. Alam and Lone (2011), found in a study that male police personnel are well-positioned in terms of emotional intelligence and psychological well-being. Emotional intelligence and psychological well-being were also found to have a strong positive relationship. According to Ahuja (2014), there is a correlation between emotional intelligence and faculty members' psychological well-being. In a 12-week follow-up study, Aranda, Extremera, and Pineda-Galán (2014) investigated emotional intelligence, life satisfaction, and subjective wellbeing in female student health professionals: the mediating impact of perceived stress. They found that participants with high emotional intelligence reported less perceived stress and they showed high levels of life satisfaction and happiness.

Table 2: summary of stepwise regressive analysis dependent variable: well-being

\begin{tabular}{llccccc}
\hline Variable & Multiple R & $\mathbf{R}^{2}$ & beta & F & sig \\
\hline 1 & Managing Emotions & .31 & .10 & .31 & 22.49 & .001 \\
2 & Motivating Oneself & .36 & .13 & .19 & 15.36 & .001 \\
\hline
\end{tabular}

Stepwise regression analysis was applied to the data as the second objective of the study was to obtain the predictors of well-being among young adults. The analysis revealed two significant predictors of well-being. Managing emotions emerged as the most pertinent predictor of well-being; as it entered the equations at step one. The $\mathrm{R}$ for this variable equals to .31 , while $\mathrm{F}$ (22.49), it is significant at .001 probabilities. Individuals high on managing emotions they handling their feelings easily, so that they are appropriate; realizing what is behind a feeling; finding ways to handle fears and anxieties, anger and sadness.

Motivating oneself as the second significant predictor of well-being. Motivating oneself entered at step two and multiple $\mathrm{R}$ increased to .36 with the entry of motivating oneself in the equation after managing emotions. The $\mathrm{F}$ ratio computed for the significance of multiple $\mathrm{R}$, at step two, equals to 15.36 which is significant at .001 . The beta value is indicating an positive relationship of motivating oneself with well-being, this indicate that individuals having good emotional control and also enjoy Well-Being.

The result of the study is well supported by the studies conducted earlier. Gallagher, et al., (2008) demonstrated that emotional intelligence significantly predicted subjective WellBeing. Parkash (2010) also found emotional intelligence is a strong predictor of well-being. Lin et al. (2016) investigated emotional intelligence was strongly predictive of well-being, emotional exhaustion depersonalization and depression. Emotional intelligence emerged as a strong predictor of resident well-being. Faraji et al. (2017) reported that emotional intelligence and perceived social support could predict life satisfaction significantly. Landa et al. (2011), evidenced that emotional intelligence is a relevant predictor of physical and mental health and psychological well-being. E.g. trait emotional intelligence is related to 
subjective well-being (Schutte \& Maouff, 2011); mental health (Martins, Ramalho, \& Morin, 2010) and happiness (Chamorro-Premuzic, Bennett, \& Furnham, 2007).

\section{Conflict of interest:}

The authors acknowledge the help of all the participants of the study. There is no conflict of interest.

\section{References}

Adler, A., \& Seligman, M. E. (2016).Using wellbeing for public policy: Theory, measurement, and recommendations. International journal of wellbeing, 6(1), 1-35.

Ahuja, A. (2014). Role of emotional intelligence in psychological well being of faculty members. ZENITH International Journal of Multidisciplinary Research, 4(10), 1-7.

Alessandri, G., Vecchione, M., Eisenberg, N., \& Laguna, M. (2015). On the factor structure of the Rosenberg (1965) General Self-Esteem Scale. Psychological assessment, 27(2), 621.

Augusto-Landa, J. M., Pulido-Martos, M., \& Lopez-Zafra, E. (2011). Does perceived emotional intelligence and optimism/pessimism predict psychological wellbeing?. Journal of Happiness Studies, 12(3), 463-474.

Brackett, M. A., \& Mayer, J. D. (2003).Convergent, discriminant, and incremental validity of competing measures of emotional intelligence. Personality and social psychology bulletin, 29(9), 1147-1158.

Carmeli, A., Yitzhak-Halevy, M., \& Weisberg, J. (2009).The relationship between emotional intelligence and psychological wellbeing. Journal of Managerial Psychology, 24(1),66-78.

Castro-Schilo, L., \& Kee, D. W. (2010).Gender differences in the relationship between emotional intelligence and right hemisphere lateralization for facial processing. Brain and cognition, 73(1), 62-67.

Chamorro-Premuzic, T., Bennett, E., \& Furnham, A. (2007). The happy personality: Mediational role of trait emotional intelligence. Personality and individual differences, 42(8), 1633-1639.

Ciarrochi, J. V., Chan, A. Y., \& Caputi, P. (2000). A critical evaluation of the emotional intelligence construct. Personality and Individual differences, 28(3), 539-561.

Dar, O. H., Alam, S., \& Lone, Z. A. (2011). Relationship between emotional intelligence and psychological wellbeing of male police personnel. Journal of the Indian academy of applied psychology, 37(1), 47-52.

Darolia, C.R. (2003). Multidimensional measure of emotional intelligence. Ambala cantt. Jagsan India Ltd.

Deci, E. L., \& Ryan, R. M. (2008).“Facilitating optimal motivation and psychological wellbeing across life's domains": Canadian Psychology, 49(1), 14 -23.

Diener, E. D., Emmons, R. A., Larsen, R. J., \& Griffin, S. (1985). The satisfaction with life scale. Journal of personality assessment, 49(1), 71-75.

Diener, E., \& Suh, E. M. (Eds.).(2000). Culture and subjective well-being. MIT press. 
Diener, E., Suh, E. M., Lucas, R. E., \& Smith, H. L. (1999). Subjective well-being: Three decades of progress. Psychological bulletin, 125(2), 276.

Emotional

Intelligence.(1998).

[online]

Retrieved

from: http://www.funderstanding.com/eq.cfm.

Extremera, N., \& Fernández-Berrocal, P. (2006). Emotional intelligence as predictor of mental, social, and physical health in university students. The Spanish journal of psychology, 9(1), 45-51.

Faraji, F., Amin, K., Arash, J., \& Laleh, D. (2017). Predicting life satisfaction: The roles of emotional intelligence, self-esteem, and perceived social support. International Journal of Indian Psychology, 4(4), 59-66.

Gallagher, E. N., \&Vella-Brodrick, D. A. (2008). Social support and emotional intelligence as predictors of subjective well-being. Personality and individual differences, 44(7), 1551-1561.

Gohm, C. L., \& Clore, G. L. (2002).Four latent traits of emotional experience and their involvement in well-being, coping, and attributional style. Cognition \& Emotion, 16(4), 495-518.

Goleman, D. (1996). Emotional intelligence. Why it can matter more than IQ. Learning, 24(6), 49-50.

Goleman, D. (1998). Working with emotional intelligence. Bantam Doubleday Dell Publishing, New York, NY.

Goleman, D. P. (1995). Emotional intelligence: Why it can matter more than IQ for character, health and lifelong achievement. Bantam Doubleday Dell Publishing, New York, NY.

Gujral, H. K., Gupta, A., \& Aneja, M. (2012). Emotional intelligence-An important determinant of well-being and employee behaviour: A study on young professionals. International Journal of Managment, IT and Engineering, 2(8), 322339.

Kaur, J. (2015). Emotional intelligence enhances well-being. Indian Journal of Applied Research, 5(3), 562-564.

Landa, J. M. A., López-Zafra, E., Martos, M. P. B., \& del Carmen Aguilar-Luzon, M. (2008). The relationship between emotional intelligence, occupational stress and health in nurses: a questionnaire survey. International journal of nursing studies, 45(6), 888901.

Lin, D. T., Liebert, C. A., Tran, J., Lau, J. N., \& Salles, A. (2016). Emotional intelligence as a predictor of resident well-being. Journal of the American College of Surgeons, 223(2), 352-358.

Lyubomirsky, S., King, L., \& Diener, E. (2005). The benefits of frequent positive affect: Does happiness lead to success? Psychological bulletin, 131(6), 803-855.

Martins, A., Ramalho, N., \& Morin, E. (2010). A comprehensive meta-analysis of the relationship between emotional intelligence and health. Personality and individual differences, 49(6), 554-564.

Matthews, G., Zeidner, M., \& Roberts, R. D. (2004). Emotional intelligence: Science and myth. Psychological Inquiry, 15(3), 179-196. 
Mavroveli, S., Petrides, K. V., Rieffe, C., \& Bakker, F. (2007).Trait emotional intelligence, psychological well-being and peer-rated social competence in adolescence. British journal of developmental psychology, 25(2), 263-275.

Mayer, J. D., Caruso, D. R., \& Salovey, P. (2000). Selecting a measure of emotional intelligence: The case for ability scales. In R. Bar-On \& J. D. A. Parker (Eds.), The handbook of emotional intelligence: Theory, development, assessment, and application at home, school, and in the workplace (pp. 320-342). Jossey-Bass.

Mayer, J. D., Salovey, P., \& Caruso, D. R. (2008). Emotional intelligence: New ability or eclectic traits?. American psychologist, 63(6), 503-517.

McIntyre, H. H. (2010). Gender differences in the nature and linkage of higher-order personality factors to trait and ability emotional intelligence. Personality and Individual Differences, 48(5), 617-622.

Mehmood, T., \& Gulzar, S. (2014). Relationship between emotional intelligence and psychological well-being among Pakistani adolescents. Asian Journal of Social Sciences \& Humanities, 3(3), 178-185.

Mikolajczak, M., Nelis, D., Hansenne, M., \& Quoidbach, J. (2008). If you can regulate sadness, you can probably regulate shame: Associations between trait emotional intelligence, emotion regulation and coping efficiency across discrete emotions. Personality and individual differences, 44(6), 1356-1368.

Mikolajczak, M., Petrides, K. V., Coumans, N., \& Luminet, O. (2009).The moderating effect of trait emotional intelligence on mood deterioration following laboratory-induced stress. International Journal of Clinical and Health Psychology, 9(3), 455-477.

Oishi, S., Diener, E., Suh, E., \& Lucas, R. E. (1999).Value as a moderator in subjective well-being. Journal of personality, 67(1), 157-184.

Palmer, B., Donaldson, C., \& Stough, C. (2002). Emotional intelligence and life satisfaction. Personality and individual differences, 33(7), 1091-1100.

Parkash,V. (2010). Emotional Intelligence and Temperament as Moderators of reactions to stress. Unpublished Doctoral Thesis. Kurukshetra University kurukshetra.

Petrides, K. V., \& Furnham, A. (2000). On the dimensional structure of emotional intelligence. Personality and individual differences, 29(2), 313-320.

Petrides, K. V., Pérez-González, J. C., \& Furnham, A. (2007). On the criterion and incremental validity of trait emotional intelligence. Cognition and emotion, 21(1), 2655.

Rosenberg, M. (1965).The measurement of self-esteem, Society and the adolescent selfimage. Princeton, 16-36.

Ruiz-Aranda, D., Extremera, N., \& Pineda-Galan, C. (2014). Emotional intelligence, life satisfaction and subjective happiness in female student health professionals: the mediating effect of perceived stress. Journal of psychiatric and mental health nursing, 21(2), 106-113.

Ryan, R. M., \& Deci, E. L. (2001). On happiness and human potentials: A review of research on hedonic and eudaimonic well-being. Annual review of psychology, 52(1), 141-166.

Ryff, C. D., \& Singer, B. H. (2008). Know thyself and become what you are: A eudaimonic approach to psychological well-being. Journal of happiness studies, 9(1), 13-39. 
Salami, S. O. (2010). Emotional intelligence, self-efficacy, psychological well-being and students attitudes: Implications for quality education. European Journal of Educational Studies, 2(3), 247-257.

Salovey, P., \& Mayer, J. D. (1990). Emotional intelligence. Imagination, cognition and personality, 9(3), 185-211.

Salovey, P., Mayer, J. D., Goldman, S. L., Turvey, C., \& Palfai, T. P. (1995). Emotional attention, clarity, and repair: Exploring emotional intelligence using the Trait MetaMood Scale.

Schutte, N. S., \& Malouff, J. M. (2011). Emotional intelligence mediates the relationship between mindfulness and subjective well-being. Personality and individual differences, 50(7), 1116-1119.

Schutte, N. S., Malouff, J. M., Simunek, M., McKenley, J., \& Hollander, S. (2002). Characteristic emotional intelligence and emotional well-being. Cognition \& Emotion, 16(6), 769-785.

Schutte, N. S., Malouff, J. M., Thorsteinsson, E. B., Bhullar, N., \&Rooke, S. E. (2007).A meta-analytic investigation of the relationship between emotional intelligence and health. Personality and individual differences, 42(6), 921-933.

Thomsen, D. K., Mehlsen, M. Y., Viidik, A., Sommerlund, B., \&Zachariae, R. (2005). Age and gender differences in negative affect-Is there a role for emotion regulation?. Personality and Individual Differences, 38(8), 1935-1946.

Van Praag, B. M., Frijters, P., \&Ferrer-i-Carbonell, A. (2003).The anatomy of subjective well-being. Journal of Economic Behavior\& Organization, 51(1), 29-49.

Waterman, A. S., Schwartz, S. J., Zamboanga, B. L., Ravert, R. D., Williams, M. K., Bede Agocha, V., ... \& Brent Donnellan, M. (2010). The Questionnaire for Eudaimonic Well-Being: Psychometric properties, demographic comparisons, and evidence of validity. The Journal of Positive Psychology, 5(1), 41-61.

World Health Organization.(1992). Assessment of subjective well-being, the subjective wellbeing inventory (SUBI) (No. Regional Health Paper No. 24). WHO Regional Office for South-East Asia.

Zeidner, M., Matthews, G., \& Roberts, R. D. (2012). What we know about emotional intelligence: How it affects learning, work, relationships, and our mental health. MIT press. 